\title{
Valor do Farelo de Arroz Integral como Fonte de Gordura na Dieta de Vacas Jersey na Fase Inicial de Lactação: Digestibilidade Aparente de Nutrientes
}

\author{
José Laerte Nörnberg ${ }^{1}$, Waldyr Stumpf Júnior ${ }^{2}$, Jorge López ${ }^{3}$, Patrícia Barcellos Costa ${ }^{4}$
}

RESUMO - Foram utilizadas oito vacas Jersey, com peso médio de 420 kg, produção média de 20 kg de leite corrigida para 3,5\% de gordura, na fase inicial de lactação (próximas ao pico de lactação), estabuladas em baias individuais, distribuídas em dois quadrados latinos (4 x 4). Objetivou-se avaliar a potencialidade do farelo de arroz integral como fonte de gordura, associado a óleo de arroz e a sebo bovino, em dietas isoprotéicas, isofibrosas e isolipídicas entre as fontes de gordura estudadas, por meio da digestibilidade aparente dos nutrientes. Os tratamentos foram: CON- concentrado sem adição de gordura; GP- concentrado com gordura protegida; FAIO- concentrado com farelo de arroz integral e óleo de arroz; FAIS- concentrado com farelo de arroz integral e sebo bovino. Os concentrados foram à base de grãos de milho moído e farelo de soja, e, como volumosos, foram empregados silagem de milho e feno de alfafa (1:1). O concentrado foi fornecido três vezes ao dia, separadamente dos volumosos. Os volumosos foram fornecidos à vontade, procurando-se manter a proporção de 55\% em relação às misturas concentradas. A estimativa da excreção fecal foi obtida com emprego de óxido de cromo e a digestibilidade da gordura por diferença. A interpretação estatística foi feita pela análise de variância dos valores médios de cada tratamento pelo teste F. As fontes de gordura não afetaram a digestibilidade aparente da matéria seca, matéria orgânica, proteína bruta, fibra em detergente neutro e de carboidratos não-fibrosos. O farelo de arroz integral pode ser usado como fonte de gordura, totalizando $6 \%$ de gordura bruta na dieta de vacas leiteiras na fase inicial da lactação.

Palavras-chave: digestibilidade, farelo de arroz integral + óleo, farelo de arroz integral + sebo, gordura protegida

\section{Value of Rice Bran as a Fat Source for Jersey Cows in Early Lactation: Apparent Digestibility of Nutrients}

\begin{abstract}
Eight Jersey cows with an average live weight of $420 \mathrm{~kg}$, yielding around $20 \mathrm{~kg}$ of $3.5 \%$ FCM in early lactation (around the peak of lactation) were used in a trial whose objectives were to evaluate rice bran as fat source associated with oil or tallow in isoproteic, iso-fibrous and iso-lipidic diets on the apparent digestibility of nutrients. Four treatments were used: CON - concentrate without fat addition; BPF- concentrate with "by pass" fat; RBO- concentrate with rice bran + rice oil; RBT- concentrate with rice bran + tallow. The concentrate was made of corn meal and soybean meal. Corn silage and alfalfa hay in a ratio of 1:1 in dry matter basis were fed ad libitum and kept in a ratio to the concentrate of 55:45\%, respectively. Concentrates were fed three times a day. Two $4 \mathrm{x} 4$ latin squares with 4-wk period were used and the means were compared by the F-test. The apparent digestibility coefficient for dry matter, organic matter, crude protein, neutral detergent fiber and nonfibrous carbohydrates was not affected by the fat sources. Rice bran can be used as fat source up to $6 \%$ of crude fat in diet for cows in early lactation.
\end{abstract}

Key Words: “by pass” fat, digestibility, rice bran + oil, rice brain + tallow

\section{Introdução}

A inclusão de fontes de gordura na dieta de vacas leiteiras tem despertado grande interesse nos últimos anos. A despeito dos benefícios não-calóricos (melhora no desempenho reprodutivo e alteração no perfil de ácidos graxos no leite), o motivo principal da suplementação com gordura têm sido a possibilidade de aumentar a produção de leite por vaca e a necessidade de aumentar a concentração energética da dieta, especialmente durante a fase inicial da lactação, quando o consumo de matéria seca não é suficiente para atender às exigências de produção de vacas de alto mérito genético (NRC, 1989: Schauff et al., 1992; Elliott et al., 1993). Neste período, o animal retira de suas reservas corporais parte dos nutrientes que irão

\footnotetext{
${ }^{1}$ Méd. Veterinário, Doutor, Professor, Núcleo Integrado de Desenvolvimento em Análises Laboratoriais (NIDAL), Departamento de Tecnologia e Ciência dos Alimentos (DTCA), Centro de Ciências Rurais (CCR), Universidade Federal de Santa Maria (UFSM), $97105-$ 900, Santa Maria - RS. E-mail: jlnornberg@mail.ufsm.br

${ }^{2}$ Eng. Agrônomo, Doutor, Pesquisador do Centro de Pesquisa Agropecuária de Clima Temperado da EMBRAPA, Pelotas-RS

${ }^{3}$ Eng. Agrônomo, PhD, Pesquisador do CNPq, Professor do Departamento de Zootecnia da Universidade Federal do Rio Grande do Sul (UFRGS).

${ }^{4}$ Méd. Veterinário, Doutorando no Departamento de Zootecnia da Universidade Federal de Viçosa (UFV).
} 
formar o leite, podendo ocorrer desordens metabólicas (acetonemia e fígado adiposo), além de problemas de fertilidade, caso a perda corporal seja excessiva (NRC, 1989).

A despeito das vantagens mencionadas, a adição de fontes naturais de gordura tem sido limitada em 5$6 \%$ da matéria seca da dieta, quando foram obtidas as melhores respostas em produção de leite (Palmquist \& Conrad, 1978). Além disso, os lipídeos podem interferir na fermentação ruminal, com redução na digestibilidade dos demais nutrientes que compõem a dieta, especialmente da fibra (fibra em detergente neutro-FDN). Em geral, os efeitos negativos dependem da quantidade e da fonte lipídica empregada, sendo que as gorduras insaturadas e os ácidos graxos de cadeia curta apresentam mais efeitos que as saturadas, enquanto os sais cálcicos de ácidos graxos (gordura protegida) apresentam efeitos mínimos sobre a fermentação ruminal (Palmquist, 1991). Outros trabalhos indicam que o aumento do aporte de cálcio da dieta minimiza os efeitos negativos na digestibilidade da fibra (Galbraith et al., 1971; EL Hag \& Miller, 1972).

O mecanismo pelo qual as gorduras interferem na fermentação microbiana ainda não é totalmente conhecido (Jenkins, 1994) e provavelmente decorre de um efeito tóxico de ácidos graxos de cadeia longa sobre as bactérias ruminais (Henderson, 1973), fundamentalmente sobre as metanogênicas e celulolíticas a determinados níveis de gordura disponível no rúmen (acima de 6\% da MS de gorduras não-protegidas na dieta) (Palmquist, 1991), pela possibilidade de formar uma capa sobre as partículas dos alimentos, interferindo, dessa forma, na aderência dos microrganismos, com conseqüente diminuição na digestão microbiana da fibra (Devendra \& Lewis, 1974).

Estudo sobre as medidas fermentativas não tem apresentado resultados consistentes, o que pode ser atribuído a fatores como a fonte de gordura, a quantidade de gordura na dieta, o grau de saturação, o comprimento da cadeia dos ácidos graxos, a estrutura da gordura (triglicerídeos ou ácidos graxos livres), assim como a taxa e a extensão da hidrólise da gordura (Getachew et al., 2001). Ácidos graxos de cadeia curta têm mostrado maior redução na digestibilidade da fibra que ácidos graxos de cadeia longa (Steele \& More, 1968; Macleod \& BuchananSmith, 1972) e ácidos graxos livres causam maior efeito negativo que na forma esterificada (Macleod \& Buchanan-Smith, 1972; Bateman \& Jenkins, 1998).
Bateman et al. (1996), usando sebo, relataram redução no consumo de matéria seca de uma dieta com pouca fibra, mas não com dieta com alto teor de fibra, sugerindo que altos níveis de fibra na dieta promovem condições adequadas para o crescimento de microrganismos que hidrolisam e hidrogenam a gordura da dieta.

Além da possível interferência na digestibilidade dos nutrientes da dieta, outro fator importante na avaliação de uma fonte lipídica é o seu próprio valor energético, que depende, principalmente, da sua digestibilidade, uma vez que a energia digestível é semelhante à energia metabolizável das fontes lipídicas e a eficiência de utilização da energia metabolizável de uma fonte lipídica é próxima de $80 \%$ (Grummer, 1995). A digestibilidade pode ser influenciada pelo consumo de matéria seca, pela quantidade de gordura consumida, pelas características da gordura na dieta basal e do suplemento lipídico (Palmquist, 1991).

Portanto, uma fonte ideal de gordura para vacas em lactação seria aquela que não interfere na digestibilidade dos demais nutrientes, mas que apresenta elevada digestibilidade intestinal. A junção destas características tem sido obtida por intermédio de técnicas industriais de proteção (como os sais cálcicos de ácidos graxos) envolvendo tanto a proteção da biohidrogenação como a proteção das bactérias ruminais da ação depreciativa dos lipídios sobre a degradação dos carboidratos (NRC, 2001), mas seu emprego tem sido restrito, especialmente em razão do preço elevado.

Diante desse fato, a alternativa seria a suplementação com fontes regionalmente disponíveis e de baixo custo, aumentando a margem bruta do produtor de leite, que geralmente é pequena, e reservando o uso das fontes protegidas artificialmente para níveis ainda mais elevados de produção.

Entre as fontes naturais disponíveis, encontra-se o farelo de arroz integral (co-produto do beneficiamento do arroz), que, em razão do seu elevado conteúdo de gordura, apresenta características potenciais para ser empregado como fonte de gordura na dieta de vacas em lactação, embora ainda não tenha sido avaliado com este propósito.

Todavia, o farelo de arroz integral apresenta ampla variação na sua composição bromatológica, incluindo-se a fração lipídica. Além disso, existe a possibilidade da interferência negativa na fermentação ruminal e na digestibilidade dos nutrientes, em razão de sua gordura ser constituída predominantemente de 
ácidos graxos insaturados, não trazendo os benefícios esperados. Mas esses efeitos negativos poderiam ser atenuados ou mesmo neutralizados, associando a gordura deste co-produto com outra fonte de gordura, seja para atingir o nível almejado de gordura na dieta seja para reduzir o seu grau de insaturação. Com características semelhantes, em termos de disponibilidade e preço, encontra-se o sebo bovino, sobre o qual pesquisas já demonstraram ser relativamente inerte no rúmen (Scauff et al., 1992; Chandler, 1993; Elliott et al., 1993; Wu et al., 1993; Drackley et al., 1994), destacando-se sua baixa digestibilidade intestinal, quando usado em quantidades elevadas (Palmquist, 1991; Grummer, 1995; Ruppert et al., 1996; Drackley, 1999).

Este trabalho foi realizado com o propósito de avaliar a potencialidade do farelo de arroz integral associado com óleo de arroz ou com sebo bovino, em comparação a uma fonte de gordura protegida e uma dieta controle (sem adição de gordura), em dietas isoprotéicas, isofibrosas e isolipídicas sobre a digestibilidade aparente dos nutrientes, em vacas Jersey suplementadas na fase inicial da lactação.

\section{Material e Métodos}

O trabalho experimental foi conduzido no Sistema de Pecuária de Leite (SISPEL) na Estação Experimental Terras Baixas (ETB) do Centro de Pesquisa Agropecuária de Clima Temperado da Empresa Brasileira de Pesquisa Agropecuária (EMBRAPA), localizado no município de Capão do Leão, RS. Foram utilizadas oito vacas da Jersey de alto mérito genético, multíparas ( $3^{\mathrm{a}}$ e $4^{\mathrm{a}}$ ordem de parição), na fase inicial da lactação (próximas ao pico de lactação), com peso médio de $420 \mathrm{~kg}$, com produção média de $20 \mathrm{~kg}$ de leite com 3,5\% de gordura/dia. Os animais foram distribuídos, ao acaso, em dois quadrados latinos $4 \times 4$, para o recebimento das diferentes dietas, sendo mantidos em dois módulos de um galpão coberto com telhas de zinco. Cada módulo foi dividido em quatro baias, cada uma equipada com comedouro, bebedouro com água potável à disposição e cama elevada do chão com piso de areia.

Foram estudados os efeitos de quatro tratamentos, dos quais três possuíam fontes diferentes de gordura: $\mathrm{CON}=$ controle sem a inclusão de gordura; $\mathrm{GP}=$ gordura protegida (sais cálcicos de ácidos graxos de óleo de palma); FAIO= farelo de arroz integral mais óleo de arroz; FAIS= farelo de arroz integral mais sebo. Ressalta-se que o propósito era utilizar como um dos tratamentos o FAI isolado como fonte de gordura. Porém, em razão do farelo adquirido apresentar 17,30\% de gordura, adicionou-se óleo de arroz a este tratamento ( $110 \mathrm{~g} / \mathrm{dia})$, com o objetivo de manter níveis semelhantes de lipídeos, proteína e fibra entre as dietas suplementadas, sem descaracterizar a composição em ácidos graxos do farelo de arroz. Utilizou-se alimentação volumosa constituída de alfafa (Medicago sativa) na forma de feno picado (2-4 cm) e planta de milho (Zea maiz) na forma de silagem (silo trincheira), em quantidades aproximadamente equivalentes, com base na matéria seca. Os concentrados foram elaborados no local, com auxílio de triturador de grãos, balanças e misturador vertical. No tratamento com sebo, este foi aquecido até se tornar líquido sendo a seguir aspergido sobre a mistura dos demais ingredientes que faziam parte do concentrado. Após a mistura, os concentrados foram ensacados, identificados e armazenados para posterior fornecimento aos animais. A participação quantitativa dos ingredientes e a composição bromatológica das dietas são apresentadas nas Tabelas 1 e 2, respectivamente.

O concentrado foi fornecido separadamente do volumoso, três vezes ao dia, após cada ordenha e por volta do meio-dia. A proporção volumoso:concentrado foi regulada para que o consumo dos animais mantivesse relação aproximada de 55:45, respectivamente. Tanto o feno como a silagem, foram amostrados diariamente, durante os períodos de coleta de dados, formando-se uma amostra composta por período experimental. As amostras de silagem foram colocadas em sacos plásticos identificados e armazenadas em congelador. As sobras de volumosos foram pesadas diariamente antes da refeição da manhã, sendo feito um ajuste de oferta do alimento quando necessário.

Os períodos experimentais foram de 28 dias. No

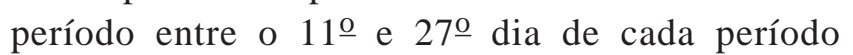
experimental, foram ministrados $10 \mathrm{~g}$ diários de óxido de cromo $(68,43 \% \mathrm{Cr})$, em duas vezes ao dia, misturados ao concentrado fornecido pela manhã e à tarde. Esse procedimento visou estimar a excreção fecal total, para determinação da digestibilidade aparente no trato digestivo. O período de coleta foi de 6 dias. Neste período, além das amostras dos alimentos oferecidos e das sobras de volumoso, também foram coletadas amostras de fezes diretamente da ampola retal, duas vezes ao dia, às 8 e 18 horas, sendo 
Tabela 1 - Composição das dietas (kg de matéria seca/dia) experimentais calculadas de acordo com o NRC (1989)* Table 1 - Ingredients composition ( $\mathrm{kg}$ of DM/day) of the experimental diets, calculated according to NRC (1989)*

\begin{tabular}{|c|c|c|c|c|}
\hline \multirow[t]{2}{*}{$\begin{array}{l}\text { Ingredientes } \\
\text { Ingredients }\end{array}$} & \multicolumn{4}{|c|}{$\begin{array}{c}\text { Tratamentos } \\
\text { Treatments }\end{array}$} \\
\hline & $\mathrm{CON}$ & GP & FAIO & FAIS \\
\hline \multicolumn{5}{|l|}{ Volumosos (Forages) } \\
\hline Alfafa, feno (Alfalfa, hay) & 4,18 & 4,18 & 4,18 & 4,18 \\
\hline Milho, silagem (Corn, silage) & 4,18 & 4,18 & 4,18 & 4,18 \\
\hline \multicolumn{5}{|l|}{ Concentrado (Concentrate) } \\
\hline Milho, grão moído (Corn, ground grain) & 4,25 & 3,45 & 2,25 & 2,83 \\
\hline Soja, farelo (Soybean, meal) & 2,39 & 2,50 & 2,35 & 2,33 \\
\hline Trigo, farelo (Wheat, bran) & - & 0,39 & - & - \\
\hline Gordura protegida (Fat, “by pass”) & - & 0,58 & - & - \\
\hline Arroz, farelo integral (Rice, bran) & - & - & 2,55 & 1,40 \\
\hline Arroz, óleo (Rice, oil) & - & - & 0,11 & - \\
\hline Sebo (Tallow) & - & & - & 0,27 \\
\hline Calcário (Limestone) & 0,07 & 0,07 & 0,20 & 0,17 \\
\hline Fosfato bicálcico (Dicalcium phosphate) & 0,18 & 0,18 & 0,8 & 10 \\
\hline Mistura mineral e vit. (Min./Vit. premix) & 0,07 & 0,07 & 0,07 & 0,07 \\
\hline Total & 15,32 & 15,60 & 15,97 & 15,53 \\
\hline
\end{tabular}

* Vacas: peso vivo médio de $420 \mathrm{~kg}$; produção média de $20 \mathrm{~kg} / \mathrm{dia}$ com 4,8\% de gordura.

* Cows: average live weight of $420 \mathrm{~kg}$; milk yielding $20 \mathrm{~kg} / \mathrm{day}$ with $4,8 \%$ of fat.

Tabela 2 - Composição químico-bromatológica das dietas experimentais (MS= matéria seca; MM= matéria mineral; $\mathrm{PB}=$ proteína bruta; $\mathrm{GB}=$ gordura bruta; $\mathrm{FDN}=$ fibra em detergente neutro; $\mathrm{CNF=}$ carboidratos não fibrosos; Ca= cálcio)

Table 2 - Chemical-bromatological composition of experimental diets (DM= dry matter; Ash= mineral matter; $C P=$ crude protein; $C F=$ crude fat; $N D F=$ neutral detergent fiber; $N F C=$ non fibrous carbohydrates; $C a=$ calcium)

\begin{tabular}{|c|c|c|c|c|}
\hline \multirow[t]{2}{*}{$\begin{array}{l}\text { Componentes } \\
\text { Components }\end{array}$} & \multicolumn{4}{|c|}{$\begin{array}{c}\text { Tratamentos } \\
\text { Treatments }\end{array}$} \\
\hline & $\mathrm{CON}$ & GP & FAIO & FAIS \\
\hline MS (\%) (DM, \%) & 57,25 & $\begin{array}{l}57,14 \\
\ldots . . \% \mathrm{~d}\end{array}$ & 57,57 & 57,62 \\
\hline MM (Ash) & 8,02 & 8,20 & 8,83 & 8,80 \\
\hline $\mathrm{PB}(C P)$ & 17,75 & 17,75 & 17,78 & 17,71 \\
\hline $\mathrm{GB}(C F)$ & 2,68 & 5,77 & 5,63 & 5,67 \\
\hline FDN (NDF) & 30,68 & 30,79 & 32,12 & 31,67 \\
\hline $\mathrm{CNF}^{*}\left(N F C^{*}\right)$ & 40,78 & 37,39 & 35,63 & 36,09 \\
\hline $\mathrm{Ca}$ & 1,07 & 1,39 & 1,15 & 1,17 \\
\hline
\end{tabular}

* $\mathrm{CNF}=100-(\% \mathrm{MM}+\% \mathrm{~PB}+\% \mathrm{~GB}+\% \mathrm{FDN})$.

${ }^{*} N F C=100-(\% A s h+\% C P+\% C F+\% N D F)$.

colocadas em sacos plásticos, identificadas e armazenadas em congelador. Ao final de cada período de coleta, as amostras de fezes foram descongeladas, retirando-se uma alíquota de $100 \mathrm{~g}$ de cada turno de coleta, e homogeneizadas, formando uma amostra composta.

As amostras de silagem, sobras de volumosos e fezes foram descongeladas à temperatura ambiente, misturadas, subamostradas, pesadas e colocadas em recipientes (sacos de papel para silagem e sobras de volumoso e pratos de alumínio para fezes) de peso conhecido sendo, então, colocadas em estufa com ventilação a $55^{\circ} \mathrm{C}$ por 72 horas. Após a retirada da estufa, as amostras foram equilibradas com a umidade do ar durante trinta minutos, pesadas e homogeneizadas. Feita a determinação da matéria parcialmente seca, as amostras foram processadas em moinho Willey com peneiras com crivos de $1 \mathrm{~mm}$ de diâmetro. Todas as amostras foram armazenadas em sacos plásticos identificados, para posterior aná- 
lise bromatológica. As amostras de feno e dos concentrados foram moídas e conservadas em frascos de vidro identificados e sob refrigeração.

Nas amostras de volumosos e suas sobras, de concentrados e de fezes, foram determinados os teores de: matéria seca (MS) a $105^{\circ} \mathrm{C}$; matéria mineral (MM), por incineração em mufla a $550^{\circ} \mathrm{C}$ durante quatro horas; de proteína bruta (PB) pelo método Kjeldahl ( $\mathrm{N}$ 6,25); e gordura bruta (GB), com éter de petróleo em aparelho Goldfish, segundo técnicas descritas na AOAC (1996). Os teores de fibra em detergente neutro (FDN) foram obtidos conforme o método de Van Soest et al. (1991) com a-amilase termoestável (Termamyl 120L do Laboratório Novozymes Latin America Limited - PR). Os teores de cromo foram determinados conforme Czarnocki et al. (1961), usando-se espectrofotometria de absorção atômica. Os ácidos graxos das fontes lipídicas foram determinados por cromatografia gasosa (AOAC, 1996).

Determinou-se o coeficiente de digestibilidade aparente (CDA) de matéria seca, matéria orgânica, proteína bruta, fibra em detergente neutro, carboidratos não-fibrosos e da fração lipídica das dietas experimentais, por meio da fórmula: $\mathrm{CDA}(\%)=$ (g do nutriente consumido - g do nutriente excretado) / g nutriente consumido X 100. A digestibilidade da gordura das fontes foi determinada pelo método da diferença (Chandler, 1993). A concentração de nutrientes digestíveis totais (NDT) foi estimada a partir da digestibilidade das frações mencionadas acima, sendo a gordura bruta multiplicada por 2,25 (Weiss, 1999).

A estimativa de produção fecal, nos diferentes tratamentos e períodos, foi obtida usando-se a concentração de cromo fecal nos animais dosificados pela fórmula: Produção fecal total $(\mathrm{PFT})=(\mathrm{g} \mathrm{Cr}$ dosificado/dia)/(g Cr/g MS fecal).

O consumo foi obtido pela diferença entre a oferta e o remanescente da matéria seca da mistura do volumoso (silagem de milho e feno de alfafa) após 24 horas de consumo, ou seja, até a manhã do dia seguinte. Dos concentrados, não houve sobras. Essas medidas foram calculadas a partir do consumo de matéria seca multiplicado pelos teores de cada fração bromatológica determinada nos alimentos oferecidos, subtraído dos valores correspondentes encontrados nas sobras de volumoso.

O modelo estatístico incluiu efeitos do quadrado latino, do animal dentro do quadrado latino, do período, do tratamento e da interação quadrado x tratamento. As variáveis estudadas foram submetidas à análise de variância e ao teste de Tukey (nível de 5\%) de comparação de médias, por intermédio do procedimento GLM (General Linear Models) do programa estatístico SAS (1998), versão 6.4.

\section{Resultados e Discussão}

Na Tabela 3, encontram-se os resultados da digestibilidade aparente no trato digestivo. Os coeficientes de digestibilidade aparente da matéria seca (MS), da matéria orgânica (MO), da proteína bruta (PB), da fibra em detergente neutro (FDN) e dos carboidratos não-fibrosos (CNF) não diferiram $(\mathrm{P}>0,05)$ com a suplementação ou não das fontes

Tabela 3 - Coeficientes de digestibilidade aparente (\%) da matéria seca (MS), matéria orgânica (MO), proteína bruta (PB), fibra em detergente neutro (FDN), gordura bruta (GB), dos carboidratos não-fibrosos (CNF) e valores (\%) de nutrientes digestíveis totais (NDT)

Table 3 - Apparent digestibility coefficients (\%) of dry matter (DM), organic matter (OM), crude protein (CP), neutral detergent fiber (NDF), crude fat (CF), nonfibrous carbohydrate (NFC), and values (\%) of total digestible nutrient (TDN)

\begin{tabular}{|c|c|c|c|c|c|c|}
\hline \multirow[t]{2}{*}{$\begin{array}{l}\text { Variáveis } \\
\text { Variables }\end{array}$} & \multicolumn{4}{|c|}{$\begin{array}{l}\text { Tratamento } \\
\text { Treatments }\end{array}$} & \multirow[t]{2}{*}{$\mathrm{P}>\mathrm{F}$} & \multirow[t]{2}{*}{$\mathrm{CV}$} \\
\hline & $\mathrm{CON}$ & GP & FAIO & FAIS & & \\
\hline MS (DM) & 63,54 & 63,46 & 62,50 & 62,89 & 0,4281 & 2,23 \\
\hline $\mathrm{MO}(\mathrm{OM})$ & 65,41 & 65,67 & 64,49 & 64,71 & 0,3558 & 2,27 \\
\hline $\mathrm{PB}(C P)$ & 62,14 & 62,85 & 63,21 & 62,50 & 0,5887 & 2,54 \\
\hline FDN (NDF) & 39,79 & 39,83 & 38,38 & 39,67 & 0,6339 & 6,52 \\
\hline $\mathrm{GB}(C F)$ & $61,20 \mathrm{~b}$ & $77,15 a$ & $74,07 a$ & $73,11 a$ & 0,0001 & 4,28 \\
\hline CNF (NFC) & 86,59 & 86,30 & 87,39 & 86,63 & 0,4075 & 1,50 \\
\hline $\operatorname{NDT}(T D N)$ & $62,49 b$ & $65,99 a$ & 64,48ab & $64,25 a b$ & 0,0018 & 2,20 \\
\hline
\end{tabular}

Médias, na mesma linha, seguidas de letras distintas, diferem $(P<0,05)$ pelo teste Tukey.

Means, in the same row, followed by different letters, differ $(P<.05)$ by Tukey test.

CV (\%) - coeficiente de variação (coefficient of variation).

R. Bras. Zootec., v.33, n.6, p.2412-2421, 2004 (Supl. 3) 
lipídicas. Porém, as dietas suplementadas apresentaram coeficiente de digestibilidade aparente da gordura bruta superiores $(P<0,05)$, sem diferença $(P>0,05)$ entre as fontes. Os valores de nutrientes digestíveis totais das dietas foram maiores $(\mathrm{P}<0,05)$ com a gordura protegida em relação ao tratamento controle, enquanto as dietas com FAIO e FAIS foram semelhantes entre si $(\mathrm{P}>0,05)$, não diferindo dos demais $(\mathrm{P}>0,05)$, ficando numericamente em posição intermediária.

Os resultados observados no presente trabalho se assemelham aos de experimentos anteriores, em que níveis de 2 a 6\% de gordura protegida não afetaram a fermentação ruminal ou a digestibilidade de nutrientes no trato digestivo de vacas em lactação (Grummer, 1988; Schneider et al., 1988; Schauff \& Clark, 1989; Coppock \& Wilks, 1991; Klusmeyer et al., 1991). A natureza "rúmen-inerte" da gordura protegida empregada (sais cálcicos de ácidos graxos de óleo de palma) provavelmente foi a responsável pela ausência de efeitos na digestibilidade da fibra. Embora sais cálcicos de ácidos graxos não sejam totalmente inertes no rúmen (Sukhija \& Palmquist, 1990; Wu et al., 1991), essa fonte, dentre as pesquisadas, é a que tem mostrado menor interferência na fermentação ruminal, o que pode ser atribuído à sua baixa solubilidade no rúmen. De acordo com revisão efetuada por Chalupa et al. (2002), a taxa de lipólise (dissociação) ruminal de sais cálcicos de ácidos graxos de óleo de palma é de apenas $6 \% / \mathrm{h}$, com uma dissociação de $47 \%$ do total dos ácidos graxos.

O farelo de arroz integral associado com óleo (FAIO), por ser uma fonte lipídica com alta proporção de ácidos graxos insaturados não-protegidos (73\%; Tabela 4), seria inibidora potencial da fermentação ruminal. Embora não se disponha de pesquisa com FAIO na dieta de vacas em lactação, mesmo com seus ácidos graxos na forma esterificada (Tortosa
\& Barber, 1979; Warren \& Farrel, 1990), a taxa de hidrólise ruminal, provavelmente seria superior à fonte de gordura protegida empregada. Como efeito comparativo, pode-se indicar os resultados citados por Chalupa et al. (2002), em que a taxa de hidrólise da gordura do grão de soja triturado foi de $35 \% / \mathrm{h}$, com uma lipólise ruminal de 83\%. Contudo, a digestibilidade da FDN não foi afetada por esta fonte de gordura. Os resultados observados diferem dos encontrados por Zhao et al. (1996), que constataram redução na digestibilidade da FDN com emprego de farelo de arroz integral na dieta de novilhos. Entretanto, esses autores utilizaram dietas com $9 \%$ de gordura, que parece ser um nível elevado. Ao mesmo tempo, corroborando os resultados observados no presente trabalho, Bateman \& Jenkins (1998) usaram óleo de soja (gordura altamente insaturada) em nível de 8\% da matéria seca da dieta e também não observaram redução na digestibilidade da fibra.

Para a fonte FAIS, a participação do sebo em praticamente $50 \%$ da fonte deve ter contribuído para torná-la menos reativa no rúmen (menor quantidade de ácidos graxos insaturados). Considerando este fato, seria esperado um efeito, no mínimo, similar à fonte FAIO, o que foi comprovado pelos resultados. Em razão da associação com farelo de arroz, a fonte FAIS apresentou $40,71 \%$ de saturados e $54,86 \%$ de insaturados (Tabela 4).

Usando o mesmo protocolo experimental, com estimativa da excreção fecal por meio do emprego de óxido de cromo, outros pesquisadores também não detectaram diferenças na digestibilidade da FDN, com diferentes fontes de gordura na dieta de vacas em lactação. Como exemplo, pode-se citar o estudo de Wu et al. (1993) utilizando gordura protegida (sais cálcicos de óleo de palma), sebo ou ácidos graxos cristalizados (prilled fat) em nível de 2,5\% sobre uma dieta com $3,7 \%$ de ácidos graxos, contendo 7,2\% de

Tabela 4 - Composição em ácidos graxos (g/100 g de gordura) das fontes de gordura Table 4 - Fatty acid composition ( $\mathrm{g} / 100 \mathrm{~g}$ of fat) of fat sources

\begin{tabular}{lccc}
\hline $\begin{array}{l}\text { Ácidos graxos } \\
\text { Fattyacids }\end{array}$ & $\begin{array}{c}\text { Gordura protegida } \\
\text { Fat “by pass” }\end{array}$ & $\begin{array}{c}\text { FAI + Oleo } \\
\text { Rice bran + oil }\end{array}$ & $\begin{array}{c}\text { FAI + Sebo } \\
\text { Rice bran + tallow }\end{array}$ \\
\hline Saturados (Saturated) & 52,54 & 21,84 & 40,71 \\
Mono-insaturados (Monounsaturated) & 35,63 & 39,48 & 37,29 \\
Poli-insaturados (Polyunsaturated) & 7,31 & 34,18 & 17,57 \\
Não identificados (Not identified) & 4,52 & 4,49 & 4,43 \\
Insaturados/Saturados (Unsaturated/Saturated) & $42,94 / 52,54$ & $73,66 / 21,84$ & $54,86 / 40,71$ \\
\hline
\end{tabular}

FAI = farelo de arroz integral (rice bran).

R. Bras. Zootec., v.33, n.6, p.2412-2421, 2004 (Supl. 3) 
semente de algodão inteira, fornecida a vacas Holandês com média de 92 dias de lactação. Nesse estudo, os resultados demonstraram que a suplementação lipídica não afetou a digestibilidade da MS ou da FDN (digestibilidade aparente média: MS = 63,20\%; FDN $=38,02 \%)$. Usando as mesmas fontes empregadas por Wu et al. (1993), Grummer (1988), Shauff \& Clark (1989), Jerred et al. (1990) e Palmquist (1991) não encontraram efeito da suplementação na digestibilidade da fibra. Também Schauff et al. (1992) não verificaram alterações na fermentação ruminal e na digestibilidade dos nutrientes com a adição de 2,2\% de sebo em dietas contendo $10 \%$ de grãos de soja. O mesmo foi constatado por Elliott et al. (1993), ao adicionarem 2,2\% de sebo com milho alto em óleo, e Drackley et al. (1994), com 5\% de sebo adicionado em dietas com mistura concentrada à base de milho e farelo de soja.

No presente estudo, a ausência de efeitos negativos do FAIO e FAIS sobre a digestibilidade da FDN nas dietas pode ser decorrente dos seguintes fatores: nível relativamente baixo de gordura na dieta basal (2,8\%); fontes de gordura com ácidos graxos na forma esterificada (triglicerídeos); quantidade de ácidos graxos insaturados condizentes com a capacidade de hidrogenação dos microrganismos no rúmen; níveis adequados de FDN (32\%) e de cálcio $(>1,0 \%)$ nas dietas; maior atividade dos microrganismos que digerem a fibra, em função da redução, embora pequena, no consumo de carboidratos não-fibrosos; e uma possível complementação digestiva da fibra no intestino grosso. Um ou mais destes fatores podem ter contribuído de forma isolada ou conjunta.

Geralmente, considera-se que uma fonte de gordura é relativamente inerte se a digestão da fibra não é alterada e se não há redução considerável no consumo de alimentos e na produção de leite (Chandler, 1993). Os resultados comprovam que tanto FAIO como FAIS apresentam essas características, podendo ser incorporados como fontes lipídicas em níveis de 3\% de gordura em dietas de vacas em lactação sem comprometer a digestibilidade dos demais nutrientes, sendo comparáveis neste aspecto a sais cálcicos de ácidos graxos de óleo de palma (gordura protegida). Entretanto, deve-se reconhecer que estes resultados se aplicam à dietas com silagem de milho e feno de alfafa como fonte de volumosos e com nível de FDN de 32\%, pois observações de outros estudos, com dietas à base de silagem de milho (Smith etal., 1993) ou baixas emplantas forrageiras (Grant \& Weidner, 1992) foram menos tolerantes a adições de gordura. Para uso mais amplo, sugere-se a continuidade de pesquisas para avaliar os efeitos dessas fontes (FAIO e FAIS) associadas com outras fontes de alimentos volumosos.

A digestibilidade da gordura bruta foi menor para a dieta controle $(\mathrm{P}<0,05)$ em comparação com as dietas suplementadas (Tabela 3). Aumentos na digestibilidade aparente da gordura bruta com suplementação lipídica na dieta basal também foram observados em outros trabalhos (Chandler, 1993), o que pode ser atribuído à diluição da fração extraída com éter (não-digestível), gordura fecal endógena e formação de sabões insolúveis (Palmquist \& Conrad, 1978; Grummer, 1988; Palmquist, 1991) ou em razão da maior digestibilidade da gordura adicionada (Jenkins \& Jenny, 1989).

Além da possível interferência na digestibilidade da fibra, outro fator importante na avaliação de uma fonte lipídica é o seu próprio valor energético, que depende, principalmente, da sua digestibilidade. $\mathrm{Na}$ Tabela 5, encontram-se os dados empregados para o cálculo e os resultados da digestibilidade da gordura das fontes estudadas.

A digestibilidade da gordura protegida foi maior $(\mathrm{P}<0,05)$ que a da gordura do farelo de arroz integral + óleo e farelo de arroz + sebo, enquanto as últimas foram semelhantes $(\mathrm{P}>0,05)$ entre si e superiores $(\mathrm{P}<0,05)$ a da gordura bruta da dieta basal. Os dados registrados na literatura são bastante variáveis, porém consistentemente mais elevados para sais cálcicos de ácidos graxos de cadeia longa que para outras fontes. Estudos de Andrew et al. (1991) acusaram digestibilidade de sais cálcicos de ácidos graxos de cadeia longa de $97 \%$. O levantamento efetuado por Chandler (1993) mostrou que a digestibilidade de fontes de gordura na dieta de vacas de alto mérito genético usando sais cálcicos de ácidos graxos de óleo de palma varia de 73 a 97\%, com média de $84,2 \%$, enquanto, para o sebo, a variação nessa medida foi de 85 a 94\%, com média de 90,5\%. Drackley (1999) registrou digestibilidades de 60 a $100 \%$ quando foram adicionados níveis de 3 até $9 \%$ de sais cálcicos de ácidos graxos (digestibilidade média de $81 \%$ com 5,5\% na dieta). Quando se considerou apenas os níveis mais baixos de inclusão de sais cálcicos de ácidos graxos (3\%), a digestibilidade variou de 91,8\% (Schauff \& Clark, 1992) a 100\% (Schauff et al., 1992), com média de

R. Bras. Zootec., v.33, n.6, p.2412-2421, 2004 (Supl. 3) 
Tabela 5 - Digestibilidade da gordura das fontes pesquisadas

Table 5 - Digestibility of fat of research sources

\begin{tabular}{|c|c|c|c|c|}
\hline \multirow[t]{2}{*}{$\begin{array}{l}\text { Itens } \\
\text { Items }\end{array}$} & \multicolumn{4}{|c|}{$\begin{array}{l}\text { Tratamentos } \\
\text { Treatments }\end{array}$} \\
\hline & $\mathrm{CON}$ & GP & FAIO & FAIS \\
\hline CMS, kgDMI, kg & 16,69 & 16,53 & 16,72 & 16,72 \\
\hline Gordura bruta (GB), \% da MS & 2,76 & 5,57 & 5,50 & 5,44 \\
\hline Crude fat (CF), \% of DM & & & & \\
\hline Consumo de GB (CGB), kg & 0,46 & 0,92 & 0,92 & 0,91 \\
\hline CF intake (CFI), $\mathrm{kg}$ & & & & \\
\hline $\begin{array}{l}\text { CGB da dieta basal, g } \\
\text { CFI of basal diet }\end{array}$ & 460 & 430 & 370 & 400 \\
\hline $\begin{array}{l}\text { CGB da fonte suplementar, } g \\
\text { CFI of supplemental source, } g\end{array}$ & 0,00 & 490 & 550 & 510 \\
\hline $\begin{array}{l}\text { Digestibilidade aparente da GB da dieta, \% } \\
\text { Apparent digestibiliity of CF diet, \% }\end{array}$ & 61,20 & 77,15 & 74,07 & 73,11 \\
\hline $\begin{array}{l}\text { GB digerida, } \\
\text { Digested } C F, g\end{array}$ & 282 & 710 & 682 & 665 \\
\hline $\begin{array}{l}\text { GB digerida da dieta basal, } g \\
\text { Digested CF of basal diet, } g\end{array}$ & 282 & 263 & 226 & 245 \\
\hline $\begin{array}{l}\text { GB digerida da fonte, } g \\
\text { Digested CF of source, } q\end{array}$ & - & 447 & 456 & 420 \\
\hline $\begin{array}{l}{ }^{*} \text { Digestibilidade aparente da GB da fonte, \% } \\
{ }^{*} \text { CF Apparent digestibility of source, } \%\end{array}$ & $61,20 \mathrm{c}$ & $91,22 \mathrm{a}$ & $82,91 b$ & $82,35 b$ \\
\hline
\end{tabular}

${ }^{*} \mathrm{P}>\mathrm{F}=0,0001 ; \mathrm{CV}$ (coeficiente de variação/coefficient of variation) $=6,89 \%$.

Médias, na mesma linha, seguidas de letras distintas, diferem $(P<0,05)$ pelo teste Tukey.

Means, in the same row, followed by different letters, differ $(P<.05)$ by Tukey test.

95,9\%. Os valores de digestibilidade da gordura protegida citados acima são semelhantes aos obtidos no presente estudo (média de 91,22\%), sendo que a maior digestibilidade dos ácidos graxos na forma de sais pode ter decorrido do maior fluxo de ácidos graxos insaturados para o intestino.

Drackley (1999) relatou ainda que a digestibilidade do sebo adicionado em níveis de 2 até $5 \%$ na dieta pode variar de 48,9 a 73,9\%, sendo que, no trabalho realizado por Ruppert et al. (1996), o nível de $2 \%$ de sebo apresentou a maior digestibilidade. O elevado grau de saturação parece ser o fator responsável pela menor digestão do sebo (Grummer, 1995). Em termos de perfil de ácidos graxos, os dados na literatura acusam correlação negativa entre a absorção intestinal e a quantidade de ácido esteárico. A absorção intestinal de fontes saturadas torna-se maior quando há presença concomitante de ácidos graxos insaturados, especialmente o ácido oléico, o que denota um efeito sinérgico na digestibilidade dos ácidos graxos saturados (NRC, 2001), provavelmente em razão de maior emulsificação no intestino (Chalupa et al., 1996). No presente trabalho, este sinergismo provavelmente ocorreu com a fonte FAIS, pois $40 \%$ da gordura do FAI correspondeu ao ácido oléico, justificando o valor mais elevado de digestibilidade de FAIS (82,35\%) quando comparado ao valor de $73,9 \%$ para o sebo isolado (Drackley, 1999). Os resultados com FAIS e com FAIO também estão de acordo com Palmquist \& Jenkins (1980), em que a digestibilidade de quantidades moderadas de gordura nas dietas (3 a 5\%) de vacas em lactação foi de cerca de $80 \%$.

\section{Conclusões}

O farelo de arroz integral, tanto associado a óleo quanto ao sebo, acusou resultados semelhantes à gordura protegida sem afetar a digestibilidade aparente da matéria seca, matéria orgânica, proteína bruta, fibra em detergente neutro e de carboidratos não-fibrosos da dieta, apresentando elevada digestibilidade da fração lipídica. Portanto, o farelo de arroz integral pode ser usado como fonte alternativa de gordura, totalizando $6 \%$ de gordura bruta em dietas de vacas leiteiras de alto mérito genético no início da lactação. 


\section{Agradecimento}

À CPACT-EMBRAPA, pela infra-estrutura e pelos recursos disponibilizados na realização deste trabalho; ao CNPTA-EMBRAPA, pelo apoio na determinação do perfil de ácidos graxos; à Mercatho Representações Ltda., pelo fornecimento da gordura protegida (Megalac- Church and Dwight Company, Inc.); e à Novozymes Latin America Ltda., pelo fornecimento da enzima Termamyl $120 \mathrm{~L}$.

\section{Literatura Citada}

ANDREW, S.M.; TYRREL, H.F.; REYNOLDS, C.K. et al. Net energy value for lactation of a dietary fat supplement fed to mature dairy cows. Journal of Dairy Science, v.74, n.8, p.2588-2600, 1991.

ASSOCIATION OF OFFICIAL ANALYTICAL CHEMISTS AOAC. Official methods of analysis. 16.ed. Arlington: 1996. 1137p.

BATEMAN, H.G.; JENKINS, D. Influence of soybean oil in higher fiber diets fed to nonlactating cows on ruminal unsaturated fatty acids and nutrient digestibility. Journal of Animal Science, v.81, n.9, p.2451-2458, 1998.

BATEMAN, H.G.; SPAIN, J.N.; ELLERSIECK, M.R. Influence of by-product feeds and tallow on lactation performance of Holstein cows during two seasons. Journal of Dairy Science, v.79, n.1, p.114-120, 1996.

CHALUPA, W.; MOATE, P.; BOSTON, R. 2002. Ruminal metabolism and intestinal digestion of fatty acids. Disponível em > $\underline{\text { http://animal.cals.arizona.edu/SWNMC/pdf/ }}$ 2002/Chalupa Moate Boston2002.pdf $>$ Acesso em setembro de 2002.

CHALUPA, W.; VECCHIARELli, B.; ELSER, A.E. et al. Ruminal fermentation in vivo as influenced by long chain fatty acids. Journal of Dairy Science, v.69, n.5, p.1293-1301, 1996.

CHANDLER, P. Digestibility of fat sources for dairy cows deserves another look. Feedstuffs, v. 65, n.15, p.1-3, 1993.

COPPOCK, C.E.; WILKS, D.L. Supplemental fat in high-energy rations for lactating cows: Effects on intake, digestion, milk yield and composition. Journal of Animal Science, v.69, n.9, p.3826-3837, 1991.

CZARNOCKI, J.; SIBBALD, I.R.; EVANS, E.V. The determination of chromic oxide in samples of feed and excreta by acid digestion and spectrophotometry. Canadian Journal of Animal Science, v.4, n.1, p.167-179, 1961.

DEVENDRA, C.; LEWIS, D. The interaction between dietary lipids and fibre in the sheep. Animal Production, v.19, n.1, p.67-76, 1974.

DRACKLEY, J.K. New perspectives on energy values and supplementation levels of supplemental fats. In: PROCEEDINGS WESTERN CANADIAN DAIRY SEMINAR, 1999, Edmonton. Proceedings... Edmonton, 1999. v.11, p.171-180.

DRACKLEY, J.K.; GRUM, D.E., McCOY, G.C. et al. Comparison of three methods for incorporation of liquid fat into diets for lactating dairy cows. Journal of Dairy Science, v.77, n.8, p.1386-1484, 1994.
ELLIOTT, J.P.; DRACKLEY, J.K.; SCHAUFF, D.J. et al. Diets containing high oil corn and tallow for dairy cows during early lactation. Journal of Dairy Science, v.76, n.3, p.775-789, 1993.

EL HAG, G.A.; MILLER, T.B. Evaluation of whisky distillers by-product. VI. The reduction in digestibility of malt distiller's grain by fatty acids and the interaction with calcium and other reversal agents. Journal of the Science of Food and Agriculture, v.23, n.2, 247-258, 1972.

GALBRAITH, H.; MILLER, T.B.; PATON, A.M.et al. Antibacterial activity of long chain fatty acids and the reversal with calcium, magnesium, ergocalciferol and cholesterol. Journal Applied Bacteriology, v. 34, n.4, 803-813, 1971.

GETACHEW, G., DePETERS, E.J., ROBINSON, P.H. et al. In vitro rumen fermentation and gas production: influence of yellow grease, tallow, corn oil and their potassium soaps. Animal Feed Science and Technology, v.93, p.1-15, 2001.

GRANT, R.J., WEIDNER, S.J. Nutrition feeding and calves. Effect of fat from whole soybeans on performance of dairy cows fed rations differing in fiber level and particle size. Jorunal of Dairy Science, v.75, n.10, p.2742-2751, 1992.

GRUMMER, R.R. Influence of prilled fat and calcium salt of palm oil fatty acids on ruminal fermentation and nutrient digestibility. Journal of Dairy Science, v.71, n.1, p.117123, 1988.

GRUMMER, R.R. Ruminal inertness vs digestibility of fat supplements: can there be harmony ? In: CORNELL CONFERENCE FOR FEED MANUFACTURERS, 57. Proceedings... Ithaca: Cornell University, 1995. p.13-24.

HENDERSON, C. The effects of fatty acid on pure cultures of rumen bacteria. Journal of Agriculture Science, v.81, n.1, p.107-112, 1973.

JENKINS, T.C. Regulation of lipid metabolism in the rumen. Journal of Nutrition, v.124, n.9, p.1372- 1376, 1994.

JENKINS, T.C.; JENNY, B.F. Effect of hydrogenated fat on feed intake, nutrient digestion, and lactation performance of dairy cows. Journal of Dairy Science, v.72, n.9, p.2316-2324, 1989.

JERRED, M.J.; CARROL, D.J.; COMBS, D.K. et al. Effects of fat supplementation and immature alfalfa to concentrate ratio on lactation performance of dairy cattle. Journal of Dairy Science, v.73, n.10, p.2842-2854, 1990.

KLUSMEYER, T.H.; LYNCH, G.L.; CLARK, J.H. Effects of calcium salts of fatty acid and proportion of forage in diets on ruminal fermentation and nutrient flow to duodenum of cows. Journal of Dairy Science, v.74, n.7, p.2220-2232, 1991.

MACLEOD, G.H.; BUCHANAN-SMITH, J.G. Digestibility of hydrogenated tallow, saturated fatty acids and soybean oil- supplemented diets by sheep. Journal of Animal Science, v.35, n.4, p.890-895, 1972.

NATIONAL RESEARCH COUNCIL - NRC. Nutrient requirements of dairy cattle. 6.ed. Washington, D.C.: National Academy of Sciences, 1989. 157p.

NATIONAL RESEARCH COUNCIL - NRC. Nutrient requirements of dairy cattle. 7.ed. Washington, D.C.: National Academy of Sciences, 2001. 381p.

PALMQUIST, D.L. Influence of source and amount of dietary fat on digestibility in lactating cows. Journal of Dairy Science, v.74, n.4, p.1354-1360, 1991.

PALMQUIST, D.L.; CONRAD, H.R. High fat rations for dairy cows. Effects on feed intake, milk and fat production, and plasma metabolites. Journal of Dairy Science, v.61, n.7, p.890-901, 1978. 
PALMQUIST, D.L., JENKINS, T.C. Fat in lactation ration: Review. Journal of Dairy Science, v.63, n.1, p.1-14, 1980.

RUPPERT, L.D., DRACKLEY, J.K., BREMMER, D.R., CLARK, J.H. Utilization of tallow by lactating dairy cows fed diets based on alfalfa haylage or corn silage. Journal of Animal Science, v.74, (suppl.) p.87, 1996.

SAS/STAT. 1998. User's guide. version 6. 4. ed. North Caroline: SAS Institute.

SCHAUFF, D.J.; CLARK, J.H. Effects of prilled fatty acids and calcium salts of fatty acids on rumen fermentation, nutrient digestibility, milk production, and milk composition. Journal of Dairy Science, v.72, n.4, p.917-927, 1989.

SCHAUFF, D.J.; CLARK, J.H. Effects of feeding diets containing calcium salts of long-chain fatty acids to lactating dairy cows. Journal of Dairy Science, v.75, n.12, p.2990-3002, 1992.

SCHAUFF, D.J.; ELLIOTT, J.P.; CLARK, J.H. et al. Effects of feeding lactating dairy cows diets containing whole soybeans and tallow. Journal of Dairy Science, v.75, n.7, p.1923-1935, 1992.

SCHNEIDER, P.; SKLAN, D.; CHALUPA, W. et al. Feeding calcium salts of fatty acids to lactating cows. Journal of Dairy Science, v.71, n.8, p.2143-2150, 1988.

SMITH, W.A.; HARRIS, JR., B.; Van HORN, H.H. et al. Effects of forage type on production of dairy cows supplemented with whole cottonseed, tallow, and yeast. Journal of Dairy Science, v.76, n.1, p.205-215, 1993.

STEELE, W.; MORE, J.H. The digestibility coefficient of myristic, palmitic and stearic acids in the diet of sheep. Journal of Dairy Research, v.35, n.2, p.371-376, 1968.

SUKHIJA, P.S.; PALMQUIST, D.L. Dissociation of calcium soaps of long-chain fatty acids in rumen fluid. Journal of Dairy Science, v.73, n.7, p.1784-1787, 1990.

TORTOSA, E.; BARBER, C.B. El salvado de arroz y su valor potencial en alimentacion animal. Mejora Animal, v.20, n.5, p. 211-219, 1979.
Van SOEST, P.J.; ROBERTSON, J.B.; LEWIS, B.A. Symposium: carbohydrate methodology, metabolism, and nutritional implications in dairy cattle. Methods for dietary fiber, neutral detergent fiber, and nonstarch polysaccharides in relation to animal nutrition. Jorunal of Dairy Science, v.74, n.10, p.3583-3597, 1991.

WARREN, B.E.; FARREL, D.J. The nutritive value of full-fat and defatted Australian rice bran. I. Chemical composition. Animal Feed Science and Technology, v.27, n.3, p.219228, 1990.

WEISS, W. Energy prediction equation for ruminant feeds. In: CORNELL NUTRITION CONFERENCE FOR FEED MANUFACTURERS, 61., 1999, Ithaca. Proceedings... Ithaca: Cornell University, 1999. p.176-185.

WU, Z.; HUBER, J.T.; SLEIMAN, F.T. et al. Effect of three supplement fat sources on lactation and digestion in dairy cows. Journal of Dairy Science, v.76, n.11, p.3562-3570, 1993.

WU, Z.; OHAJURUKA, O.A.; PALMQUIST, D.L. Ruminal synthesis, biohydrogenation, and digestibility of fatty acids by dairy cows. Journal of Dairy Science, v.74, n.9, p.3025-3034, 1991.

ZHAO, Y., TANIGUCHI, K.; OBITSU, T. Effects of different processing for rice bran on dietary nutrient digestion in each segment of the digestive tract of steers. Animal Feed Science Technology, v.59, n.4, p.265-277, 1996. 